\title{
NIGERIA AND THE DIALECTICS OF MULTICULTURALISM
}

\author{
Cyril Udebunu \\ doi: http://dx.doi.org/10.4314/og.v8i1.1
}

\begin{abstract}
In the last chapter of his Science and the Modern World, Alfred Whitehead finely submitted that "a diversification among human communities is essential for the provision of the incentives and material for the Odyssey of the human spirit". He believed that other tribes or nations of different habits should not be seen as enemies but as godsends since we require of them "something sufficiently akin to be understood, something sufficiently different to provoke attention, and something great enough to command admiration". One should not expect from them all the virtues. On the contrary "we should even be satisfied if there is something odd enough to be interesting". He said all these to condemn any 'Gospel of Uniformity', and to uphold the values of multiculturalism which is one of those avenues of expression of cultural tolerance and human diversity; a positive way of broadening narrow horizons and exposing people to the wide range of cultural heritages. As a multicultural nation with more than 250 languages and several ethnic groups, Nigeria is such an excellent ground where the various powers and riches of these groups can be orchestrated. However, where the Gospel of 'one Nigeria' is interpreted as uniformity by trying to make Nigeria one of the tribes of the multiple tribes, harmonizing the diverse economic, political and religious cultures of its parts, one is persuaded to ask: if the country understands what our origins are and what the principles of multiculturalism mean?
\end{abstract}

\section{Introduction}

In the aftermath of the failed coup d'etat of 1966 which was viewed as ethnic based, there have been deliberate moves to forge Nigerians into a system of government that tries to "homogenize" the diverse economic, political and religious cultures in the country. These attempts included for instance, the take-over of Christian schools and the regional universities by the federal military government in 
the 1970s, the deployment of soldiers as governors or administrators in states other than their own and with traditions and cultures different from those of their states of origin and finally, the surreptitious enrolment of Nigeria in the Organization of Islamic States. These shots were aimed at making Nigeria a single homogenous state by eroding the social and cultural autonomy of the regions that constitute the Federal Republic of Nigeria. Today, as Nigeria bask herself in the joy of 50 years of Independence, the confidence on the indivisibility and oneness of Nigeria seems to grow in strength. The senate president David Mark expressed it overtly that the 50 long years of Nigeria's existence as a single nation is a sign of her character of indivisibility. According to him, 'at independence in 1960, many believed that the people were so different to remain together as one people for a long time, however we have proven them wrong and remained indivisible."

But, it is presumed that David Mark is not ignorant of the fact that the seeming togetherness the nation enjoyed has been an uncomfortable one, and there are signs every where threatening to tear this nation apart. Indeed, Nigeria's unity has been a fragile one pointing to some intrinsic problem bordering on the ethnic affiliations, and the lack of true ingredients of multiculturalism which is neither homogeneity forcibly being foisted on Nigerians nor a total disconnect. It is the aim of this article to show how this nation has gone wrong in building a true multicultural state, then demonstrate the values of multiculturalism and indicate how it can be lived in the one house called Nigeria.

\section{Definitions}

As a term, multiculturalism has been used in a variety of ways. Andrew Heywood distinguished between two overall forms: descriptive and normative. Used descriptively, he said, "it has been taken to refer to cultural diversity", but as a normative term, it has been seen as "a positive endorsement, even celebration of communal diversity, typically based on either the right of different groups to respect and recognition or to the alleged benefits to the larger society of moral and cultural diversity." Stacy Wong describes it as "the coexistence of many cultures in a society, without any one culture 
dominating the region. It seeks to overcome any form of discrimination such as racism". 3

Multiculturalism therefore refers literally to a plurality of cultures. Here, the term 'culture' points to the collective material and non-material accomplishments of particular groups, their ways of life and the manner in which these patterns of behaviour are transmitted from one generation to the next. Its strong points are usually seen in its broadening of narrow horizons and exposing people to the wide range of cultural heritages. It presents however, problem when seen in the sense of politicized group identities vis-àvis individual human rights in democracies because, treating groups equally is much more difficult than treating individuals equally.

To be a multicultural person means, according to John Walsh, "not how much a man knows but what intellectual depth and breadth he has and how he relates it to other central and universally important problems." 4 What is universal about the multicultural person is an abiding commitment to the essential similarities between people everywhere, while paradoxically maintaining an equally strong commitment to differences. A universal person "does not at all eliminate culture differences". Instead, he or she, says Walsh, "seeks to preserve whatever is most valid, significant, and valuable in each culture as a way of enriching and helping to form the whole." ${ }^{5}$ Because a multicultural person is the embodiment of the universal and the particular, he is said to be an integration of the great philosophers of both the East and the West.

Multiculturalism therefore has in view the whole society through its national identity, but does equally challenge the perceived homogeneous national identity. Ellie Vasta maintained that multiculturalism 'is not antithetical to, but rather a reformer of national identity'. Nations need only pay attention to its constituent entities, respect and recognise their interests. True, 'it does not make sense to encourage a strong minority identities and weak national identities. Strong multicultural identities are something good, but they need a framework of vibrant, dynamic, national narratives and the ceremonies and rituals which give expression to a national identity. For, if there is nothing strong enough, purposive and 
inspiring to integrate into, what is the need for the integration'? ${ }^{6}$ This is usually perceived in people's cynicism when they say they can not die for their country, which is indicative of lack of strong national values for which one can be proud of and can make sacrifices for, or a protest to identify with one's nation because of feeling of neglect or discrimination.

As a philosophical concept, multiculturalism enjoys a more recent history. It began as part of pragmatism, -a movement at the end of the $19^{\text {th }}$ century which later developed into a political and cultural pluralism at the turn of the $20^{\text {th }}$ century. This was possible due to the new wave of European penetration and control of the subSaharan Africa and secondly, the colossal immigration of Europeans to the United States. Consequently, a number of philosophers like William James, George Santayana, John Dewey developed concepts of cultural pluralism, from which emerged what is known today as multiculturalism. ${ }^{7}$

\section{Nigeria and Prototypes of Multicultural States}

When Nigeria once made the policy on language that every student in secondary school must offer one national language outside one's own mother tongue in WASC (West African School Certificate) examinations, the essence was to facilitate understanding, respect and love with an aim to improving the feeling of oneness as a nation. However, this educational policy has now been jettisoned from the school curriculum. The nation has drifted from rules and practices meant to make Nigeria a truly multicultural nation, to unite all her citizens as belonging to one house while respecting their differences. Today, the emphasis is on English as lingua franca and the only language requisite for admission into higher studies. This has brought untold effects on the life of this nation by reducing love and interest in the cultures and especially the languages of the groups that make up this nation.

It is on account of the lack of such basic element of multiculturalism that the German Chancellor Angela Merkel decried the failure of the aims of multiculturalism in her own land and indeed, in the world at large. She said that the so-called "multikulti" concept where people of different backgrounds could "live side-beside" happily has not worked: 'The approach to build a multicultural 
society and to live side-by-side and so enjoy each other...has failed, utterly failed. ${ }^{8}$ For her, immigrants of her land needed in addition to their languages to learn German, but this was not the case. The Muslim immigrants try to stampede the German way of live and language and make no bone about their disdain for German culture. This is why one thinks that Germans may have had some good reason to fear for their culture, their nominal Christian beliefs and their very existence as a nation of a given culture in Europe.

But, has multiculturalism actually failed? The answer depends on various factors, that is, on how one evaluates the elements of multiculturalism; the manner diverse nations had tried to implement them; and the various groups' adjustment to these principles. The case of Switzerland and South Korea offer another side of the story of the voyage of the 'multikulti' concept. South Korea is known to be among the world's most ethnically homogeneous nations.' However, the word "multiculturalism" has become wide spread among the Koreans today. In his article entitled "Multicultural Korea: Celebration or Challenge of Multiethnic Shift in Contemporary Korea?", Han Geon-Soo noted as follows: "As the increase of foreign migrants in Korea transforms a single-ethnic homogenous Korean society into multiethnic and multicultural one, Korean government and the civil society pay close attention to multiculturalism as an alternative value to their policy and social movement." ${ }^{10}$ The many cultures which find themselves in Korea have been so harmoniously lived that according to Stephen Castles,

Korea no longer has to decide whether it wants to become a multicultural society. It made that decision years ago - perhaps unconsciously - when it decided to be a full participant in the emerging global economy. It confirmed that decision when it decided to actively recruit foreign migrants to meet the economic and demographic needs of a fastgrowing society. Korea is faced by a different decision today: what type of multicultural society does it want to be?",11 
Comparing Korea's earlier homogeneity to her present day multiculturalism, JoongAng Daily maintained that while the former had been one of its greatest strengths, the cornerstone that helped it survive adversity, it has also its downside. For then the people were immersed in their culture and were thus blind to its characteristics and quirks, having shared values and views and supporting decisions even when they are obviously bad. Multiculturalism, on the other hand, introduced contrasting views and challenged existing assumptions. While it undermined the homogeneity, it enriched Koreans with a better understanding of themselves. ${ }^{12}$

Another country is Switzerland, which from birth is characterized by cultural, linguistic, religious and regional diversities. As a country, it has existed for more than seven centuries in spite of her aforementioned diversities. What were the factors responsible then for her success? Linda tells us in her book, Swiss Democracy: Possible Solutions to Conflict in Multicultural Societies, that Switzerland had been successful because the Swiss have over the years developed unique institutions aimed at minimizing any conflict emanating from such differences. In the first place, she said, "Switzerland renounced the idea of creating a oneculture, one language nation-state. Second, the Swiss were able to develop a type of democracy that favours and enforces political power-sharing between Protestants and Catholics, between the German-speaking majority and French, Italian and Romanischspeaking minorities, and between organized employers and trade unions." " ${ }^{13}$ These measures, according to her, had led tremendously to the "social integration, peaceful conflict resolution by negotiation, and national consensus amongst a once- fragmented and heterogeneous population." 14

Switzerland is a shining example to other multicultural societies struggling to manage their various differences. It is a democracy that resonates well with traditional forms of African governance. While commending Swiss approach to multicultural societies, Linda insisted, for example, that the challenge is not only the construction of more inclusive institutions which reflect the needs and concerns of all citizens. The challenge is also to change attitudes so that citizens respect difference and are aware of their rights and 
responsibilities in a democracy, and act accordingly. Of course, Swiss consociational democracy cannot simply be imported to Nigerian soil, especially given the specificity of the conditions prevailing in Nigeria for instance. However, the Swiss experience is fascinating and holds some valuable insights for Nigerian scholars and policy-makers.

\section{Nigeria and the Multicultural Dialectics}

From the preceding discussion, Switzerland presents a scenario fairly akin to Nigeria especially from the point of view of nations formed through amalgamation of different regions speaking different languages. Belgium is also not different for it is made up of people originating from Germany, Netherlands and France with corresponding German, Dutch and French languages. At the arrival of the British people, Nigeria was virtually non existent. The amalgamation of the three regions: northern, eastern, and western into what is now known as Nigeria, was a much later reality created out of many scattered autonomous nations (mainly Hausa, Igbo and Yoruba). And when the union took place, the country was then administered as still three autonomous regions held together by the existence of a colonial governor-general appointed by the colonial office in London.

At that time, each region had constitutional powers to regulate its education, trade, agriculture, health care, and judiciary. Each was allowed to develop and modernize its culture and society at its own pace. Nothing in the manner they administered the country suggested they would have preferred the total obliteration of the diverse cultural identities and diversities they met in Nigeria. Even their policy of indirect rule, as distinct from the French assimilation policy showed this preference of a system of multiculturalism made possible and nurtured in federalist state, to a system of monoculturalism which the false homogeneous system Nigeria tends to present itself suggests. All this, of course, is not to say that multiculturalism has not its burden, like the effects of religious differences and conflicts shown in the scattered attacks of Moslem dominated Hausa against Christian dominated Igbo, etc. 
Certainly, culturally diverse countries face far greater challenges in nation-building than homogeneous societies. But these challenges are nothing to compare to the psychological trauma of losing one's integral cultural identity and language, or above all, the riches of cultural exchanges. There can be conflicts, but these conflicts can be resolved, not through assimilation into a homogenous cultural identity. Switzerland is one of the few multilingual countries in Europe that does not have political difficulties with its linguistic minorities for instance. Yet it would be fundamentally wrong to think of Switzerland as a country without historical conflicts. Modern Switzerland was not created by one homogeneous ethnic people but by different ethnic groups speaking different languages and following different religions. As in other countries, her processes of nation building, industrialization, urbanization and modernization were accompanied by societal conflicts. But over the past 150 years, Switzerland has been fortunate to find political ways of achieving multicultural understanding; this has been based mainly on the concept that Switzerland renounced the idea of creating a culturally homogeneous nation-state. ${ }^{15}$

The right of every nationality group to practice its culture: religious, economic, social and political should be respected more than any form of socio-political constructs. The stability of Nigeria depends more on fashioning an ethos of mutual respect among the nationality groups that make up Nigeria than on efforts by any government (military or its surrogates) to create a make-shift unity devoid of equality and justice. Restoring and enhancing autonomy for the constituent regions or states will certainly create an enabling environment for each region or group of nationalities to develop its culture in a framework where differences are respected and healthy inter-regional competition brought in to replace the current ethos of hate and distrust engendered by the politics of domination that has characterized Nigeria's government. 'Nigeria', writes Remi Oyeyemi 'is a multicultural society. It is a conglomerate of nations with different peoples and cultures. It is a basket of different religions and world-views. It is a country which expectations of its peoples, other than remaining as one (the proof of which is not even self-evident) are different., ${ }^{16}$ 
Remy regretted we have been so much in a hurry to identify ourselves as one Nigeria by throwing overboard our "source of being," the cultural context that gives meaning to the variety of individual existence. According to him, it is from its cultural milieu that each ethnic group in Nigeria derives its relevance and identity, hence meaning and purpose for existence. The culture "not only underscores the values that individuals or groups from such ethnic group would continue to cherish or detest as they traverse the length and breadth of universe, it also gives them uniqueness, hence their pride and self-esteem. Man cannot operate in cultural abstract." 17

As a recipe for Nigeria's growth and development therefore, he recommended the need to recognize that none of the ethnic groups, big or small share a uniform dream about Nigeria. Our world-views are completely different: Our expectations from our leaders, our notions of government, our moral standards, our perceptions and understanding of religion, our ideas of how to live and regulate our lives, our goals and missions as individual ethnic groups, all these are different. He pointed out that "while a group would want their children to go to school, some others would want theirs to go to the farms and Mosques. Whereas a group could relate with men of another faith without any friction, another is odiously intolerant. While some are willing to move along with the twenty-first century and be a part of the world, others want to bask in the bliss of the blind Stone Age'. He emphasized however that these choices have nothing wrong with them, only that each ethnic group should be allowed to make their different choices, being different people with different cultures, dreams, hopes and aspirations'. ${ }^{18}$

Alfred Whitehead finely maintained that "a diversification among human communities is essential for the provision of the incentives and material for the Odyssey of the human spirit". He believes that other tribes or nations of different habits should not be seen as enemies but as godsends since we require of them "something sufficiently akin to be understood, something sufficiently different to provoke attention, and something great enough to command admiration". One should not expect from them all the virtues. On the contrary "we should even be satisfied if there 
is something odd enough to be interesting." clearly in order to pronounce any 'Gospel of Uniformity' as dangerous. To him, therefore, multiculturalism is one of the excellent avenues mankind can demonstrate cultural tolerance and celebrate human diversity; a positive way of broadening narrow horizons and exposing people to the wide range of cultural heritages.

Thus, Nigeria must not shy away from its reality of a multicultural state. With more than 250 languages and several ethnic groups, Nigeria is an excellent ground where the various powers and riches of mankind can be orchestrated. The concept of "One Nigeria" as a play ground or an encompassing theatre where all the various National groups can display with respect these diverse riches of cultures and talents is an irresistible invitation. But, where 'One Nigeria' is construed in terms of assimilating into one by homogenizing the diverse economic, political and religious cultures of the country, one must not readily give in. This is why the efforts of the former governor of the Central Bank of Nigeria, Prof. Charles Soludo deserves praise by stopping one of those attempts as he removed the Arabic writings on the face of all our currency notes for the three major languages of the country -this is a true sense of multiculturalism.

Nigerians should continue to live as one and yet different. The satellite (local) cultures must continue to be satellite (local) and thereby play a larger part in the world at large. That is what T.S. Eliot also maintained in his Christianity and Culture, when he emphasized that the survival of the satellite culture is of very great value to the stronger culture. It is of no gain whatsoever for English culture, for instance, if the Welsh, Scots and Irish become indistinguishable from Englishmen. If this were to happen, they would all become indistinguishable featureless "Britons" at a lower lever of culture than that of any of the separate regions. On the contrary, it is of great advantage for English culture to be constantly influenced from Scotland, Ireland and Wales. ${ }^{20}$

Indeed, Nigeria can neither be too united nor too divided if her diverse cultures are to thrive. This is the principle of multiculturalism. Eliot tells us actually that many reasons exist against consenting to complete absorption of smaller culture into a stronger culture. The first and the most profound of these objections, 
he said, "is the instinct of every living thing to persist in its own being. The resentment against absorption is sometimes most strongly felt, and most loudly voiced, by those individuals in whom it is united with an unacknowledged awareness of inferiority or failure." 21 On the other hand, regional or satellite cultures cannot exercise meaningful influence on the stronger culture or at the national level if it decides to exist in isolation. Likewise, he points out how generally advantageous it is when for instance, Bretons closely associate with the French and the Welsh with the English. According to him, "an association of Brittany and Wales which ruptured their connexion with France and England respectively would be an unqualified misfortune. For a national culture, if it is to flourish, should be a constellation of cultures, the constituents of which, benefiting each other, benefit the whole." ${ }^{22}$ This makes the point why Nigeria must remain as one, but how the gospel of 'One Nigeria' must be interpreted. Whereas the unity of the country Nigeria is collectively agreed on, that unity cannot be purchased at the expense of the various regional groups and cultural heritages.

While insisting on the need for unity and the sacredness of the territorial oneness of Nigeria, there is need for a creative approach to the problems facing the Nigerian state. Ethiopia has produced a model that can facilitate the resolution of half a century crisis of development brought upon Nigeria through its politics of sitting on the feathers and announcing the slogan of unity that is not backed up by any imaginative response to the issues facing Nigeria's social and cultural diversity. It is seemingly imperative that only a system of unfettered autonomy over all matters of cultural, social, political, and economic development can ensure the politics of persuasion and participation that multi-national or multiethnic democracies require.

\section{Conclusion}

Indeed, we have seen that Nigeria has many reasons why it should remain as one country. It's social, cultural, ecological and religious diversities from the constituent regions are sources of advantage. But, in the wake of some surreptitious political tinkering like secretly registering Nigeria into the conference of Islamic nations or 
inscribing the Islamic logo on practically all the table forks and knifes in the market, one must view the effort as hauling a bad taste. It is an attempt to bring all into one melting pot, eliminating some regional cultural or religious heritages and foisting on every citizen the culture of one region as symbol of our national character. Such attempt to create a monocultural country out of an area with centuries of multiculturalism is completely misguided and lacks any good future. Nigeria is not endowed with opportunities for creating a melting pot but prospects to creatively optimize its inherent salad bowl of cultures.

In choosing to be multicultural, there are bound to be problems, but we must not for the problems which multiculturalism is prone to entrench set aside the values which it encapsulates. Actually, the regional cultures can be antagonistic to the national life as some have criticised. In the relations of any two cultures says Eliot, there are always two opposite forces balancing each other; attraction and repulsion -without the attraction they could never affect each other, and without the repulsion they would never survive as distinct cultures; one would absorb the other, or both would be fused into one culture. ${ }^{23} \mathrm{We}$ recognize that the various parts that constitute Nigeria must have in some way, some common characteristics or 'culture', but this can only be actual in diverse local manifestations, implying that we would aspire to a common culture which will yet not diminish the particularity of the constituent parts. A multinational society like Nigeria can reconcile unity and diversity provided it does not confuse unity with uniformity and seek comprehensive cultural uniformity among its ethnic nationalities. Nigeria should evolve its unity out of its diversity by encouraging its cultural communities to evolve a plural national culture that both reflects and transcends them.

Finally, we emphasize that to fully succeed in this enterprise of creating a truly multicultural Nigeria, a society that will be at ease with itself, there are necessary steps the federal or central government must take. Among them are: The central government should not subject the ethnic nationalities to intended or unintended discrimination. On the contrary, it should show them equal respect and give them equal opportunity to flourish. Secondly, the government should ensure social justice and equal access to political 
power among its ethnic nationalities and promote inter-ethnic and inter-religious cooperation in all aspects of life. It should finally, evolve a national identity which neither excludes nor legitimizes alone any of its communities. Where possible, national symbols, ceremonies, functions, representations etc. should reflect the multicultural character of the Nigerian society. Nigeria should be so defined that it belongs to all its citizens and not just to its dominant ethnic or religious group. It is only when this is done that we can start sipping from our diverse well of riches and ready to 'defend Nigeria's unity'. 


\section{References}

${ }^{1}$ A. Dunia, "Nigeria'll Remain Indivisible -Mark" in Daily Sun, Friday, October 1, 2010, p. 7.

${ }^{2}$ Heywood, Political Ideologies, 4th edition, Palgrave Macmillan, 2007: p. 313.

${ }^{3}$ S. Wong, "Multiculturalism in Malaysia and Singapore" in Helium, 8 Oct. 2006, hpp//www.helium.com/items/81482

$4 \mathrm{~J}$. Walsh, Intercultural Education in the Communication of Man, Honolulu: The University of Hawaii Press, 1973.

${ }^{5}$ Ibid.

${ }^{6}$ E. Vasta "Accommodating Diversity: Understanding Multiculturalism" April 16th, 2009 http://www.confluence.org.uk/2009/04/16/accommodating-diversityunderstanding-multiculturalism/.

${ }^{7}$ Cf. Boening, Astrid B. "Euro-Islam -A Constructivist Idea or a Concept of the English School?", in European Union Miami Analysis (EUMA), (Miami-Florida European Union Center of Excellence) 4 (12): (May 2007), pp. 3-10.

${ }^{8}$ See Daily Sun, Oct. 18, Nigeria, 2010, p. 14.

${ }^{9}$ Cf. The Korea Herald. August 2, 2006.

${ }^{10} \mathrm{H}$. Geon-Soo, "Multicultural Korea: Celebration or Challenge of Multiethnic Shift in Contemporary Korea?", Korea Journal, Vol.47 No.4, Winter 2007, pp.32-63.

${ }^{11}$ S. Castles, "Will Labour Migration lead to a Multicultural Society in Korea? Global Human Resources Forum 2007 / International Migration Institute http://www.imi.ox.ac.uk/Korea\%202007.pdf

12 P. Underwood, "Multiculturalism in Korea", in JoongAng Daily, August 26, 2010.

${ }^{13}$ L. Wolf Swiss Democracy: Possible Solutions to Conflict in Multicultural Societies, New York: St. Martin's Press Inc., 1998, p. xviii.

${ }^{14}$ Ibid.

${ }^{15}$ Ibid.

${ }^{16} \mathrm{R}$. Oyeyemi, "THISDAY And the Kaduna Riots: Symptom of A Simmering Nigerian Tragedy", in Nigeriaworld, Monday 25, 2002, http//nigeriaword.com/cgi.-bin/axs/ax.pl

${ }^{17}$ Ibid.

${ }^{18}$ Ibid.

${ }^{19}$ A. Whitehead, Science and the Modern World, in Great Books, P. W. Goetz (Ed.) Chicago: Encyclopaedia Britanica inc. vol. 55, 1991, p. 233. 
${ }^{20}$ T.S. Eliot Christianity and Culture, New York: A Harvest/HBJBooks, 1968, pp. 128-129

${ }^{21}$ Ibid. p. 128

${ }^{22}$ Ibid. p. 132

${ }^{23}$ Ibid. p. 135 